LA-UR- $\quad 98=1 \% 94$
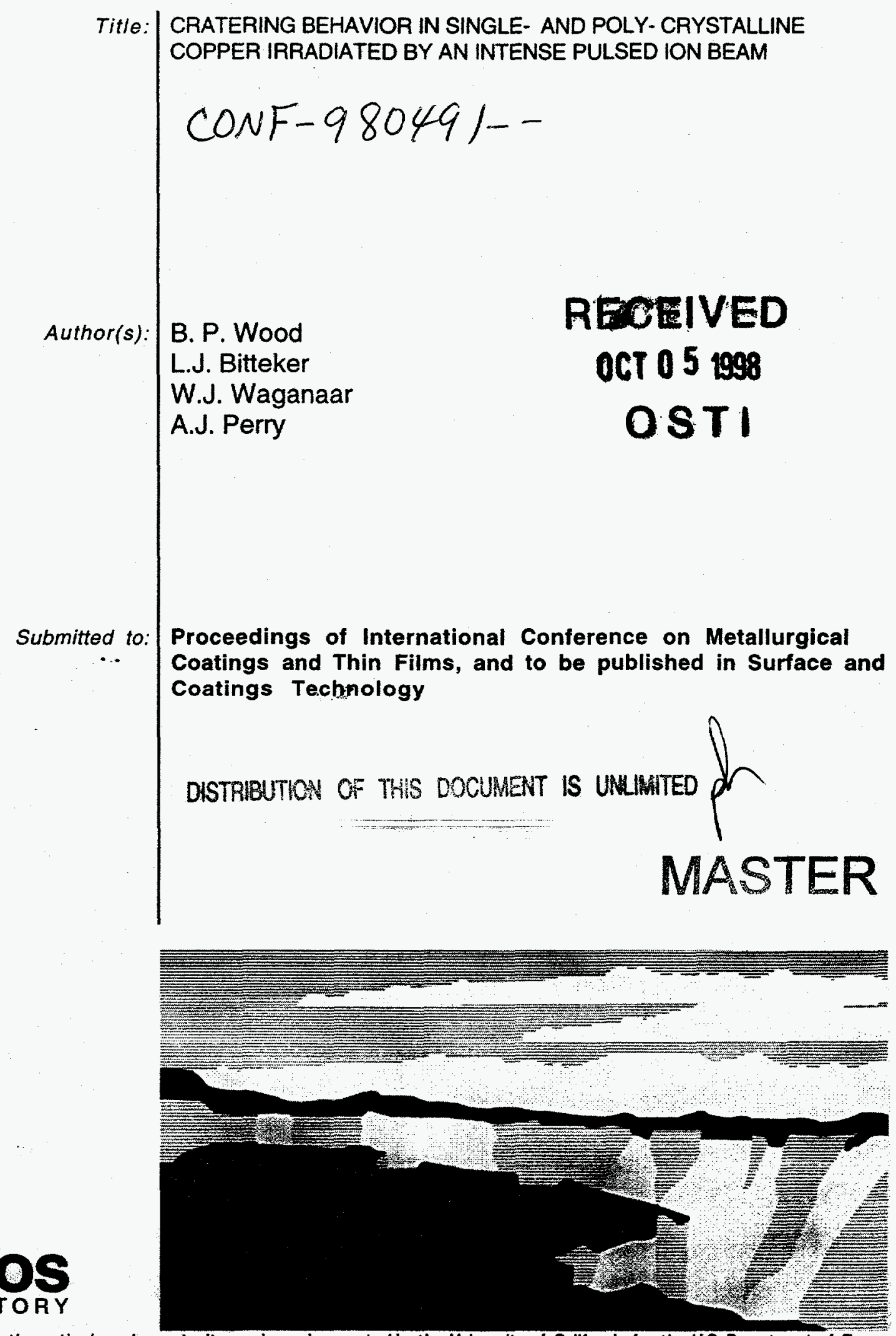

Los Alamos National Laboratory, an affirmative action equal opportunity employer, is operated by the University of California for the U.S. Department of Energy under contract W-7405-ENG-36. By acceptance of this article, the publisher recognizes the the U.S Government retains a nonexclusive, royalty-free license to puplish or reporduce the published form of this contribution, or to allow others to do so, for U.S Government purposes. The Los Alamos National Laboratory requests that the publisher identify this article as work performed under the auspices of the U.S Department of energy. 


\section{DISCLAIMER}

This report was prepared as an account of work sponsored by an agency of the United States Government. Neither the United States Government nor any agency thereof, nor any of their employees, makes any warranty, express or implied, or assumes any legal liability or responsibility for the accuracy, completeness, or usefulness of any information, apparatus, product, or process disclosed, or represents that its use would not infringe privately owned rights. Reference berein to any specific commercial product, process, or service by trade name, trademark, manufacturer, or otherwise does not necessarily constitute or imply its endorsement, recommendation, or favoring by the United States Government or any agency thereof. The views and opinions of authors expressed herein do not necessarily state or reflect those of the United States Government or any agency thereof. 


\section{DISCLAIMER}

Portions of this document may be illegible in electronic image products. Images are produced from the best available original document. 


\title{
Cratering Behavior in Single- and Poly-Crystalline Copper Irradiated by an Intense Pulsed Ion Beam
}

\author{
B. P. Wood, L. J. Bitteker, W. J. Waganaar \\ Plasma Physics Group, MS-E526, Los Alamos National Laboratory, Los Alamos, NM 87545 \\ A. J. Perry \\ A.I.M.S. Marketing, 10921 Corte Calandria, San Diego, CA 92127
}

\begin{abstract}
When treated with intense pulsed ion beams (IPIB), many materials exhibit increased wear resistance, fatigue life, and hardness. However, this treatment often results in cratering and roughening of the surface. In this work, high purity single crystal and polycrystalline copper samples were irradiated with pulses from an IPIB to gain insight into the causes of this cratering behavior. Samples were treated with $1,2,5$, and 10 shots at $2 \mathrm{~J} / \mathrm{cm}^{2}$ and $5 \mathrm{~J} / \mathrm{cm}^{2}$ average energy fluence per shot. Shots were about $400 \mathrm{~ns}$ in duration and consisted of a mixture of carbon, hydrogen, and oxygen ions at $300 \mathrm{keV}$. It was found that the single crystal copper cratered far less than the polycrystalline copper at the lower energy fluence. At the higher energy fluence, cratering was replaced by other forms of surface damage, and the single crystal copper sustained less damage at all but the largest number of shots. Molten debris from the Lucite anode (the ion source) was removed and redeposited on the samples with each shot.
\end{abstract}

\section{Introduction}

Intense Pulsed Ion Beams (IPIB) have been under investigation for a number of years in Japan, the Former Soviet Union, Germany, and the United States for materials processing applications [1-7]. Such IPIB devices typically produce beams of 10's of kiloamps current at 100's to 1000's of kilovolts, in pulses of 50-1000 ns. Although these are called "ion beams", they are, in fact beams of neutral plasma - although only the ions are initially accelerated, electrons are pulled off surfaces to provide quasi-neutrality.

When treated with by IPIB, many materials exhibit increased wear resistance, fatigue life, and hardness. However, this treatment often results in cratering and roughening of the surface [810], which undergoes rapid melting and resolidification. Although IPIB treatment of pure materials such as copper [8,9] and silicon [11] has been studied, it is not clear whether this cratering damage results from alloy content, explosive behavior of impurities at grain boundaries, grain structure itself, or impact of debris on the molten surface.

In the work reported here, high purity single crystal and polycrystalline copper samples were irradiated with pulses from an IPIB to gain insight into the causes of this cratering behavior. Samples were treated with $1,2,5$, and 10 shots of 400 ns duration at $2 \mathrm{~J} / \mathrm{cm}^{2}$ and $5 \mathrm{~J} / \mathrm{cm}^{2}$ average energy fluence per shot. Following treatment, the samples were examined for damage with a scanning electron microscope. 


\section{Experimental Apparatus}

Experiments were performed on the Anaconda IPIB at Los Alamos National Laboratory (LANL) [12]. Anaconda utilizes the ballistically focused, magnetically insulated ion diode shown in

Figure 1. Ions are formed by the

flashover of a conical annulus of Lucite attached to the anode electrode. Ions are accelerated across a $300 \mathrm{kV}$ gap toward nested, truncated metal cones that form the cathode. Field emitted cathode electrons are prevented from shorting the anode-cathode gap by a transverse magnetic field generated by pulsed electromagnets which surround the cathode cone. The azimuthal $E \times B$ drift of electrons in the anodecathode gap causes them to stay confined. The diode is connected directly to a Marx generator operated to produce a $300 \mathrm{keV}, 30$ $\mathrm{kA}, 400 \mathrm{~ns}$ beam of carbon, hydrogen, and oxygen ions. The ballistic focus of the diode produces a minimum spot size of about $100 \mathrm{~cm}^{2}$, yielding energy fluences at focus of about $30 \mathrm{~J} / \mathrm{cm}^{2}$. This energy fluence is sufficient to ablate material. Since we desired to rapidly melt and resolidify the

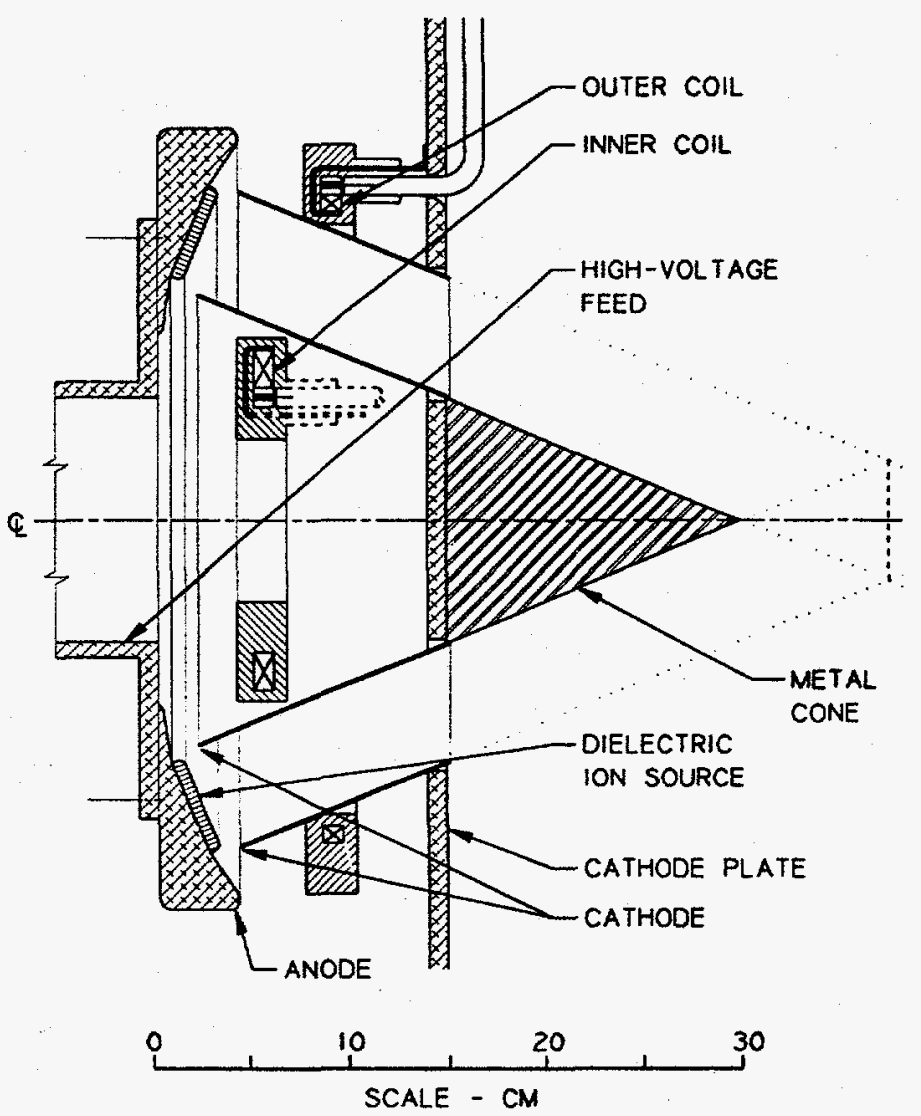

Figure 1. The Anaconda ballistically focused, magnetically insulated ion diode. surface, we placed the samples past the focal plane, in the divergent cone of the beam. The particular location which yielded the desire energy fluence was determined calorimetrically by observing the temperature rise on a $0.64 \mathrm{~mm}$ thick titanium sheet placed in the beam with an Inframetrics model 600 fast infrared camera at $10 \mu \mathrm{m}$ wavelength through a salt vacuum window [13]. This arrangement was also used during treatment to monitor the energy of each shot. There was a relatively large variation in energy fluence from shot to shot - in a typical sequence of shots, energy fluences would vary between about half the average to one and a half times the average. This resulted mostly from spatial inhomogeneities in the beam created by differences in the flashover behavior of the Lucite anode. Since we were out of the focal plane, the annular beam was effectively an image of the anode, which "lit-up" more strongly in some locations than others. The energy fluences described here as 2 and $5 \mathrm{~J} / \mathrm{cm}^{2}$ are averages over the shot sequence. 
Images shown here were obtained using a JEOL 6300 FX field emission scanning electron microscope (SEM), maintained by the Center for Materials Science at LANL. An accelerating voltage of $1 \mathrm{kV}$ was used.

\section{Experimental Results and Discussion}

Samples of high purity (99.999\%), electropolished single crystal and polycrystalline copper, silicon wafer, 600 grit roughened $75 \% \mathrm{Cu} / 25 \% \mathrm{Ni}$ alloy, and lathe turned aluminum bronze $(76 \% \mathrm{Cu}, 14.5 \% \mathrm{Al}, 5.5 \% \mathrm{Fe}, 2 \% \mathrm{Mn}, 2 \% \mathrm{Co})$ were placed in the beam path for treatment. Only results for the pure copper and silicon will be reported here; results for the $\mathrm{Cu} / \mathrm{Ni}$ alloy and aluminum bronze will be reported in a future publication. Sets of samples were given $1,2,5$, and 10 shots each at $2 \mathrm{~J} / \mathrm{cm}^{2}$ and $5 \mathrm{~J} / \mathrm{cm}^{2}$ average energy fluence per shot. The samples were wipe cleaned with alcohol before treatment, and remained in the vacuum chamber between shots

(a)
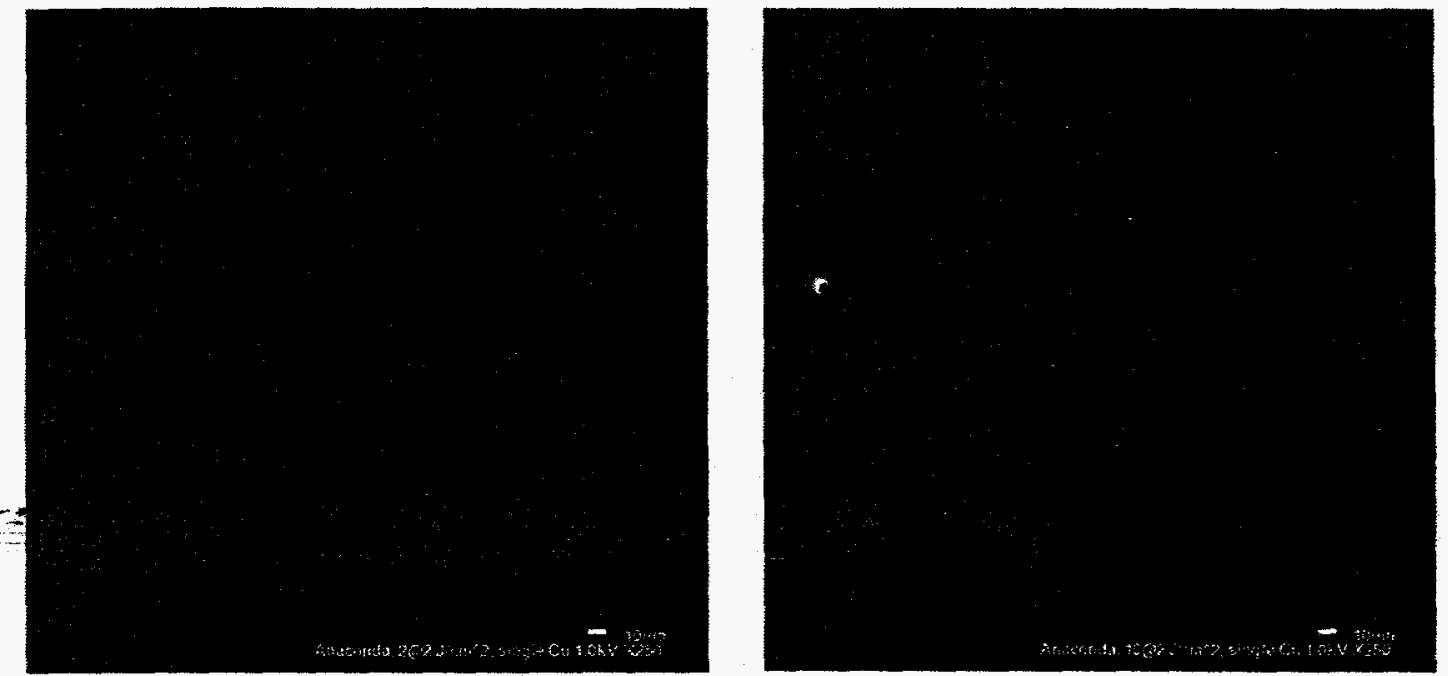

(b)
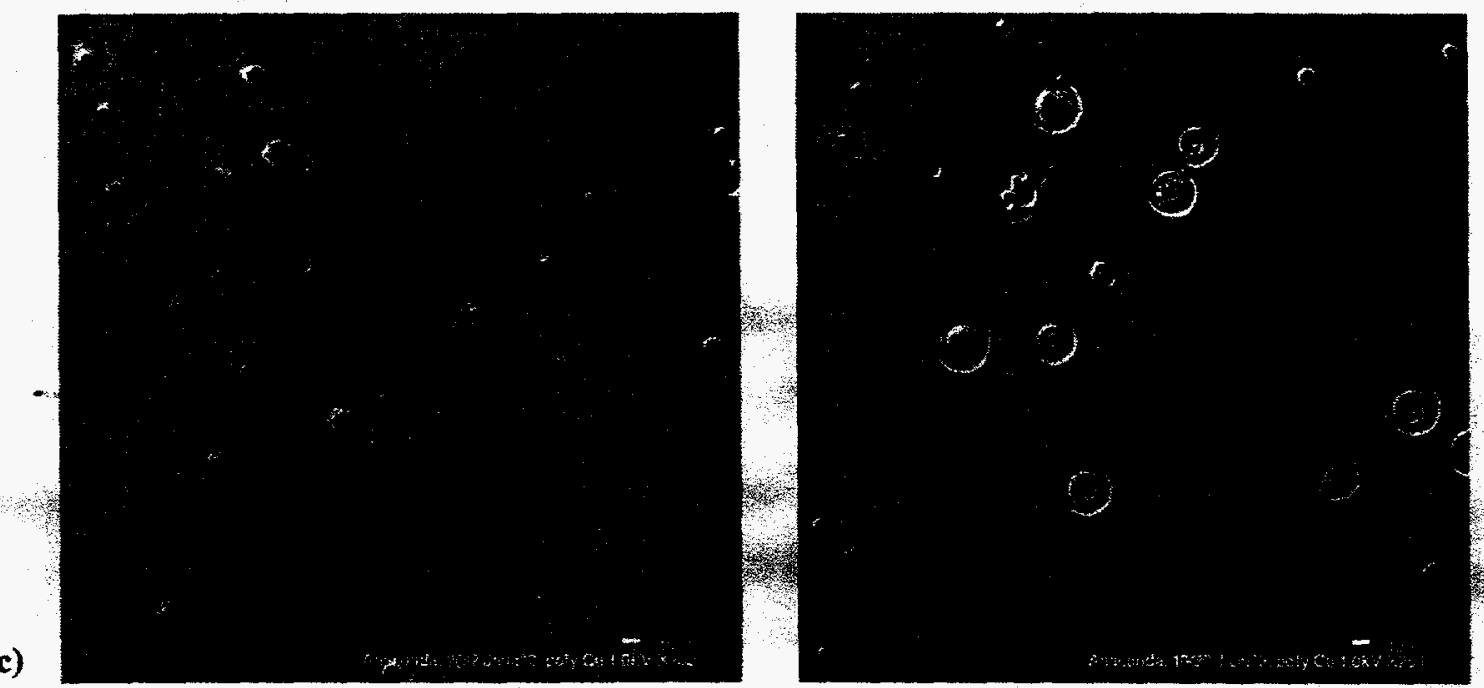

(d)

Figure 2. $250 \times$ magnification view of samples treated at $2 \mathrm{~J} / \mathrm{cm}^{2}$ per shot: (a) single crystal copper, 2 shots. (b) single crystal copper, 10 shots. (c) polycrystalline copper, 2 shots. (d) polycrystalline copper, 10 shots. 
in each sequence. Following treatment, all samples except the silicon were ultrasonically cleaned in acetone before having profilometer scans of surface roughness made (to be reported in a future publication), and being observed under the SEM. The silicon was not cleaned, so that the amount of Lucite anode debris deposited on the surface during treatment could be determined.

At all but the highest energy fluences and number of shots, the single crystal copper displayed less cratering than the polycrystalline copper, although the single crystal copper surface was roughened, and some craters were observed. Figures $2 \mathrm{a}, \mathrm{b}$ show the surface of the single crystal copper after 2 and 10 shots at $2 \mathrm{~J} / \mathrm{cm}^{2}$, and Figures $2 \mathrm{c}$,d are the comparable images for the polycrystalline copper. Note that the craters in Figures $2 \mathrm{c}$, d are of uniform size, about $25-45 \mu \mathrm{m}$ in diameter, appear to be spread randomly over the surface, and that there are less well defined

(a)
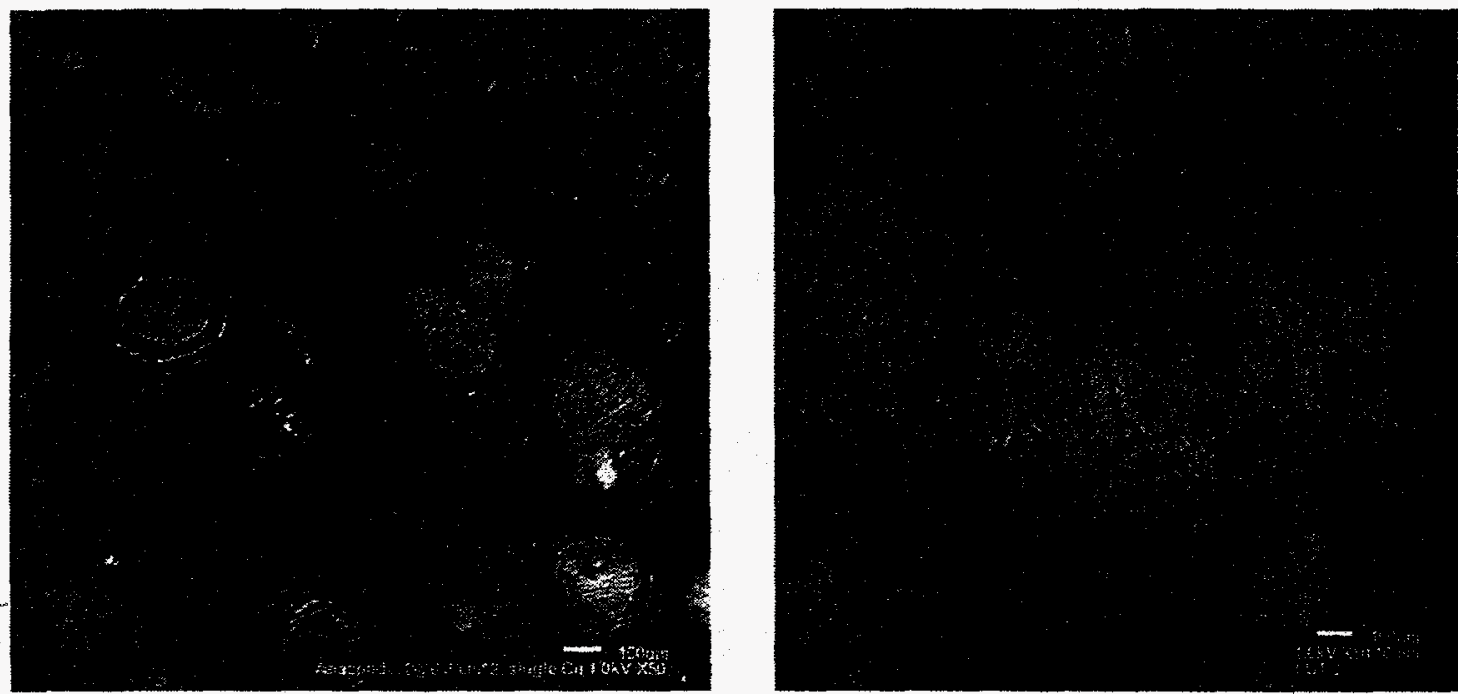

(b)

(c)
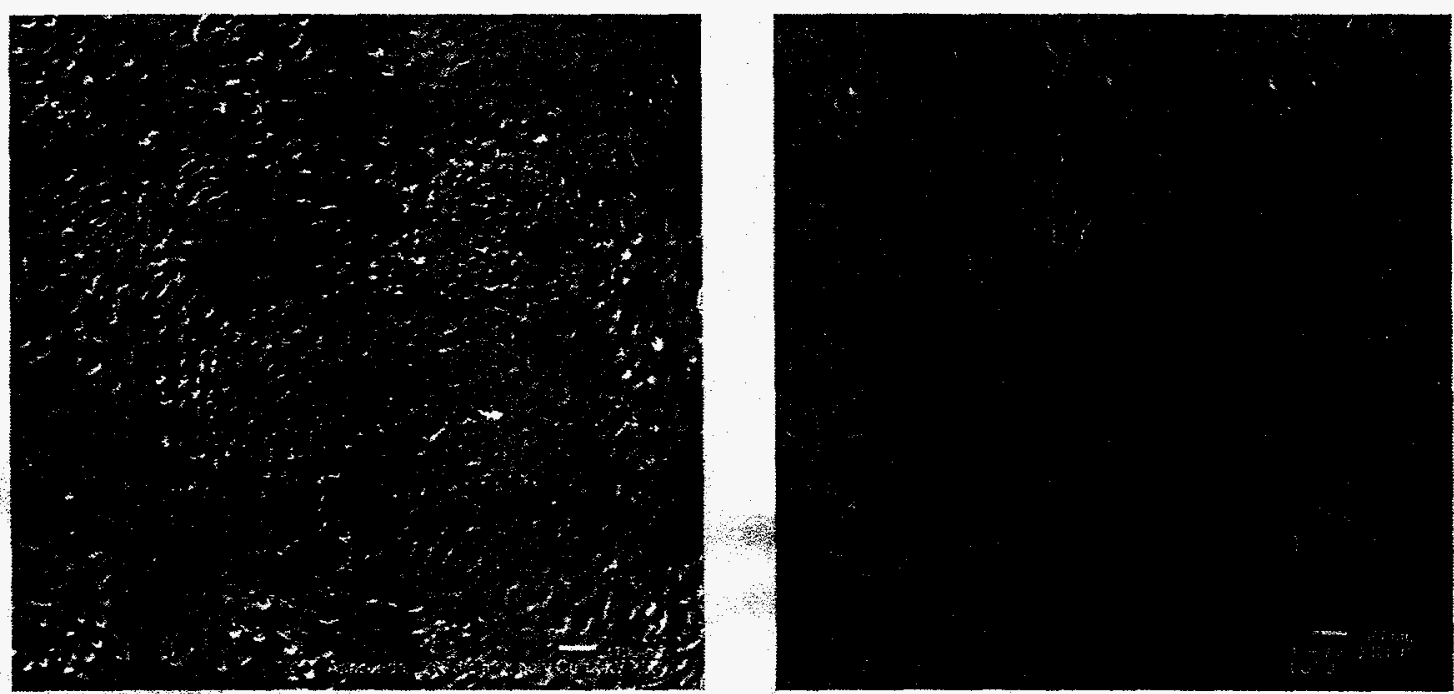

(d)

Figure 3. 50 $\times$ magnification view of samples treated at $5 \mathrm{~J} / \mathrm{cm}^{2}$ per shot: (a) single crystal copper, 2 shots. (b) single crystal copper, 10 shots. (c) polycrystalline copper, 2 shots. (d) polycrystalline copper, 10 shots. 
craters present, presumably created on earlier shots and then smoothed by the rapid melt/resolidification of the surface. The "scrape" marks in Figure $2 c$ are believed to be surface contamination from handling before the SEM images were made. Figures $3 a-d$ are the $5 \mathrm{~J} / \mathrm{cm}^{2}$ counterpart of Figures $2 a-d$, although lower magnification views are shown because the damage feature size is larger. Figures $4 \mathrm{a}, \mathrm{b}$ show the surface of the polycrystalline copper at $5 \mathrm{~J} / \mathrm{cm}^{2}$ at the same magnification as used in Figure 2. Note that well defined craters like those seen at 2 $\mathrm{J} / \mathrm{cm}^{2}$ are mostly absent at this energy fluence. Instead, there is rippling of the surface. For the highest total energy fluence ( 10 shots at $5 \mathrm{~J} / \mathrm{cm}^{2}$ ), the amount of surface damage on the single crystal and polycrystalline copper appears comparable.

(a)
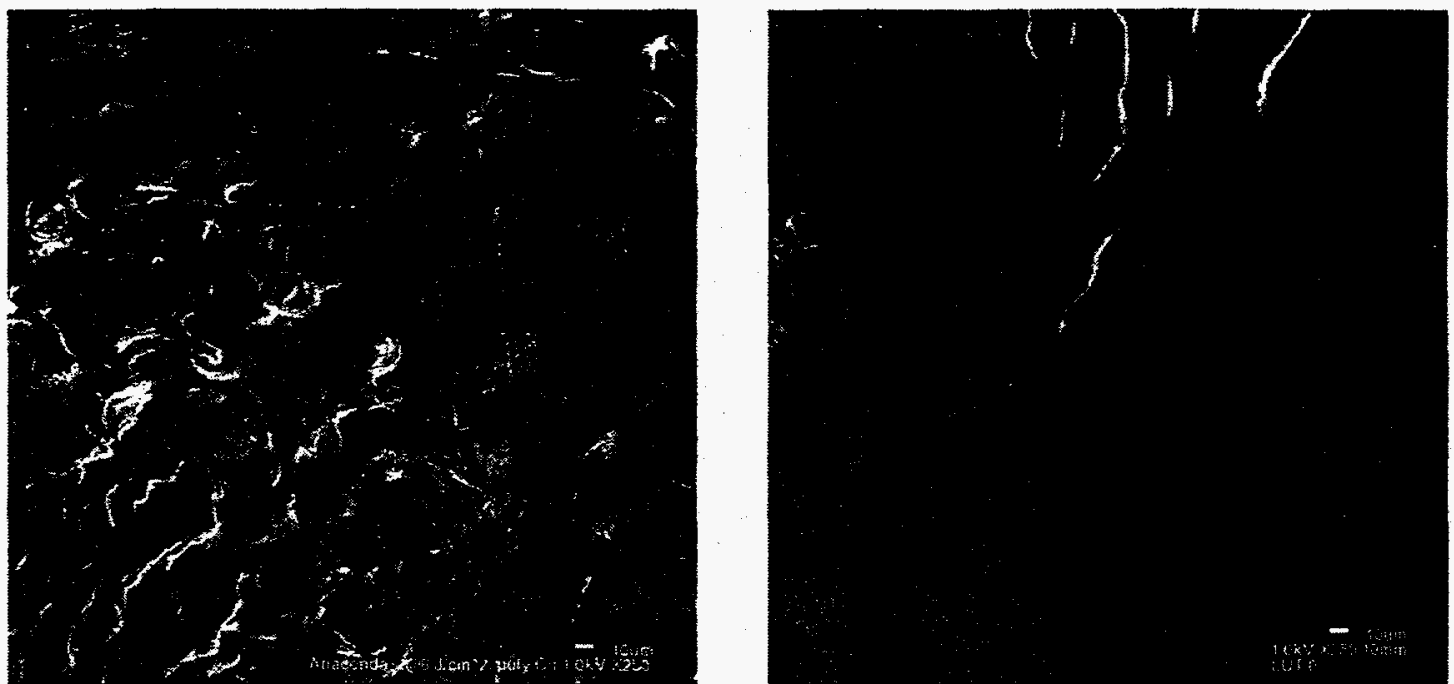

Figure 4. $250 \times$ magnification view of samples treated at $5 \mathrm{~J} / \mathrm{cm}^{2}$ per shot: (a) polycrystalline copper, 2 shots. (b) polycrystalline copper, 10 shots.

(a)
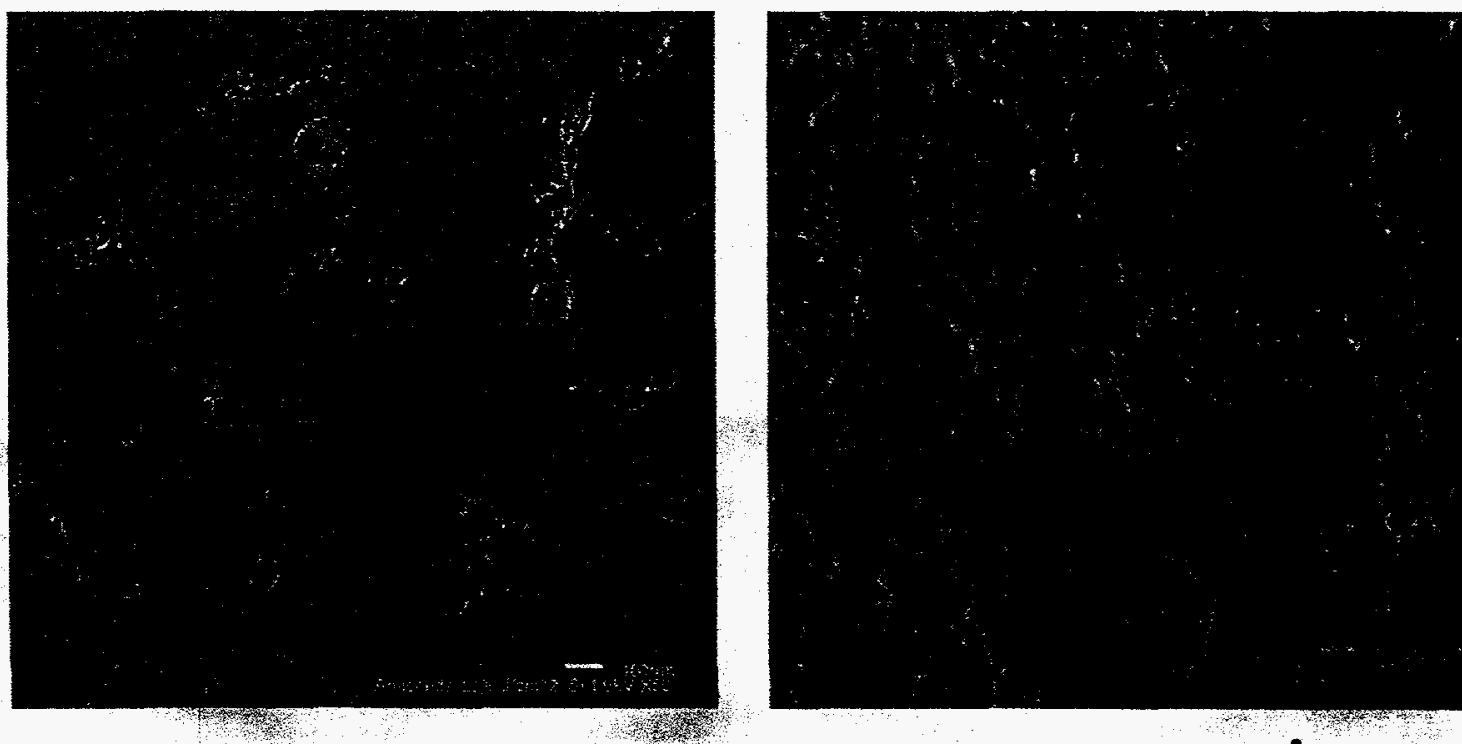

(b)

Figure 5. 50x magnification view of Lucite anode debris deposited on silicon at $5 \mathrm{~J} / \mathrm{cm}^{2}$ per shot after (a) 2 shots, (b) 10 shots. 
Of particular interest are the light colored round features in Figure 3a. We believe these are areas where large blobs of Lucite anode debris were deposited on the first shot. These blobs protected the surface (perhaps not completely) during the second shot. This is suggested by Figures 5a,b, which show the uncleaned silicon surface for 2 and 10 shots at $5 \mathrm{~J} / \mathrm{cm}^{2}$. The black spots are blobs of Lucite which appear to have been molten on impact. Some of these blobs are the size of the round features in Figure 3a. Note that the density of blobs in Figure $5 \mathrm{~b}$ is no greater than in Figure 5a (in fact, it appears to be slightly less), although the surface in Figure 5b received five times as many shots. This suggests that the blobs deposited (presumably after the ions) on one shot are removed by the ion fluence of the next shot.

\section{Conclusions}

At low energy fluence $\left(2 \mathrm{~J} / \mathrm{cm}^{2}\right)$ a high density of distinct craters were observed on high purity polycrystalline copper, but not on high purity single crystal copper. This suggests (1) that cratering is not due to alloy content, and (2) cratering is not due to impact upon the molten surface by debris. It appears that craters reform in different locations on each shot. Since impurities concentrate at grain boundaries, the impurity level there might be very much higher than the overall $10^{-6}$ concentration. Therefore, we cannot definitively distinguish between effects due solely to grain boundaries and those due to low levels of impurities. At higher energy fluence $\left(5 \mathrm{~J} / \mathrm{cm}^{2}\right)$, the distinct craters do not appear, but are replaced by ripples and waviness in the surface. For low numbers of shots at this energy fluence, the single crystal copper still shows less damage than the polycrystalline copper, however, as the number of shots increases this difference is reduced.

Molten debris from the Lucite anode is deposited upon the samples with every shot, and is removed by the ion fluence on the next shot at the energy fluences tested. This prevents a surface-shielding layer of Lucite from building up on the surface and reducing the surfacealtering efficiency of succeeding shots, although some protective effects from one shot to the next are observed.

\section{References}

[1] V.M. Bystritskii and A.N. Didenko, High-Power Ion Beams, American Institute of Physics, New York, 1989.

[2] K. Baumung, H.J. Bluhm, B. Goel, P. Hoppe, H.U. Karow, D. Rusch, V.E. Fortov, G.I. Kanel, S.V. Razorenov, A.V. Utkin, and O.Yu. Vorobjev, Laser and Particle Beams, Vol. 14, no. 2, Cambridge University Press, Boston, 1996, p. 181.

[3] M. Yatsuzuka, Y. Hashimoto, T. Yamasaki, and H. Uchida, Jpn. J. Appl. Phys. 35 (1996) 1857.

[4] A.J. Perry and J.N. Matossian, in C.R. Clayton, J.K. Hirvonen, and A.R. Srivatsa (eds.), Advances in Coatings Technologies for Surface Engineering, The Minerals, Metals \& Materials Society, 1997, p. 3. 
[5] D.J. Rej, H.A. Davis, J.C. Olson, G.E. Remnev, A.N. Zakoutaev, V.A. Ryzhkov, V.K. Struts, I.F. Isakov, V.A. Shulov, N.A. Nochevnaya, and R.W. Stinnett, J. Vac. Sci. Tech. A 15 (1997) 1089.

[6] B.P. Wood, I. Henins, W.A. Reass, D.J. Rej, H.A. Davis, W.J. Waganaar, R.E. Muenchausen, G.P. Johnston, and H.K. Schmidt, Nucl. Inst. Meth. Phys. Res. B 96 (1995) 429.

[7] G.E. Remnev, I.F. Isakov, M.S. Opekounov, G.I. Kotlyarevsky, V.L. Kuruzov, V.S. Lopatin, V.M. Matvienko, M.Yu. Ovsyannikov, A.V. Potyopmkin, and V.A. Tarbokov, Surf. Coat. Tech. 96 (1997) 103.

[8] A.D. Pogrebnjak, I.F. Isakov, M.S. Opekunov, Sh.M. Ruzimov, A.E. Ligachev, A.V. Nesmelov, and I.B. Kurakin, Phys. Lett. A 123 (1987) 410.

[9] A.D. Pogrebnjak, Phys. Stat. Sol. A 117 (1990) 17.

[10] D.J. Rej, H.A. Davis, M. Nastasi, J.C. Olson, E.J. Peterson, R.D. Reiswig, K.C. Walter, R.W. Stinnett, G.E. Remnev, and V.K. Struts, Nucl. Inst. Meth. Phys. Res. B 127 (1997) 987.

[11] R. Fastow, Y. Maron, and J. Mayer, Phys. Rev. B 31 (1985) 893.

[12] D.J. Rej, R.R. Bartsch, H.A. Davis, R.J. Faehl, J.B. Greenly, and W.J. Waganaar, Rev. Sci. Instr. 64 (1993) 2753.

[13] H.A. Davis, R.R. Bartsch, J.C. Olson, D.J. Rej, and W.J. Waganaar, J. Appl. Phys. 82 (1997) 3223. 